\title{
Crohn Disease-Associated Colorectal Adenocarcinoma
}

National Cancer Institute

\section{Source}

National Cancer Institute. Crohn Disease-Associated Colorectal Adenocarcinoma. NCI

Thesaurus. Code C96497.

A colorectal adenocarcinoma that develops in patients with a history of Crohn disease. 